
gain an understanding of the current needs of radar users.

To maintain the important operational capabilities of the WSR-88D, and to address its operational deficiencies, the strengths and limitations of the system and their effects on users must be assessed. As discussed by Morss et al. (2005), incorporating user needs at the beginning and throughout the research and development process is pivotal to producing the most usable scientific knowledge or information. The Joint Action Group for Phased Array Radar Project (JAG/PAR) surveyed upper-level management at federal agencies that use the WSR-88D network about their radar needs, marking a first step toward this end. The survey included open-ended questions about weather and aviation surveillance capabilities and requirements and about future radar needs (see appendix G in OFCM 2006). A few of the future weather and aircraft surveillance needs voiced by agencies were improved coverage of the lowest $3 \mathrm{~km}$, update rates of $1 \mathrm{~min}$ or less, and shorter data latency. A detailed description of agency responses is available online (see www.ofcm.gov/r25-mpar/ fcm-r25.htm).

Another recent survey, conducted by the Radar Operations Center (ROC), investigated volume coverage pattern usage and needs of NWS forecasters (Steadham 2008). In this study, $62 \%$ of the respondents $(N=80)$ voiced a need for faster scanning. These respondents specified that more frequent low-elevation scans (37\%) and faster volume coverage patterns (VCPs; 25\%) were the most important scanning strategy improvements. Although both of

AFFILIATIONS: LADUE-University of Oklahoma's Center for Analysis and Prediction of Storms, Norman, Oklahoma; HeINSELMAN*_-University of Oklahoma's Cooperative Institute for Mesoscale Meteorological Studies, Norman, Oklahoma; NeWman ${ }^{+}$- Cornell University, Ithaca, New York

A supplement to this article is available online (10.1175/2009BAMS2830.2) *CURRENT AFFILIATION: NOAA/OAR National Severe Storms Laboratory

+CURRENT AFFILIATION: University of Oklahoma School of Meteorology

CORRESPONDING AUTHOR: Daphne LaDue, OU Center for Analysis and Prediction of Storms, 120 David L. Boren Blvd, Suite 2500, Norman, OK 73072

E-mail: dzaras@ou.edu

The abstract for this article can be found in this issue, following the table of contents.

DOI:10.1175/2009BAMS2830.I

In final form 4 December 2009

(C)2010 American Meteorological Society the aforementioned studies (OFCM 2006; Steadham 2008) provide information about perceived radar needs, descriptions of the operational issues driving them are limited and both studies involved only federal stakeholders.

We explore how the strengths and limitations of current radar systems impacted two groups, one of which is outside the government: NWS and broadcast meteorologists. We investigated their needs by obtaining stories about their experiences with weather radars. This approach, called the critical incident technique (CIT), reveals how radar capabilities affect operations.

CRITICAL INCIDENT TECHNIQUE. CIT is an effective way of gathering specific, factual information about human behavior. It has been used in a variety of fields and is easily adaptable in qualitative research (e.g., Oliver and Roos 2003; Kraaijenbrink 2007; Schluter et al. 2008). A critical incident is a description or observation of an event in which someone's actions had clear purpose or intent, and definite consequences. In this study, critical incidents were stories illustrating how weather radar affected a meteorologist's ability to perform his/her job.

Each interview, conducted using CIT as described by Dunn and Hamilton (1986), can include anywhere from a few to several incidents. An exhaustive list of needs has likely been achieved when $\sim 100$ incidents yield no new information. Most studies scale below that level, however, according to practical limitations and desired use of results (Dunn and Hamilton 1986). Dunn and Hamilton caution that CIT is most effective when participants prepare for the interview and carefully consider what incidents they deem most significant to their job. Failure to prepare may result in stories that focus on less important matters.

Our goal was to identify at least three major operational deficiencies for each stakeholder group and thus illustrate the value of this type of study to the early development of new technology.

Participants. We used a purposive sampling strategy (Patton 2002) to seek participants for this study. NWS meteorologists were chosen because their mission includes providing weather forecasts and warnings. Meanwhile, we chose broadcast meteorologists because several studies have confirmed that most people receive and monitor weather information from their local TV broadcasters, particularly during severe convective weather (e.g., Legates and Biddle 1999; Schmidlin and King 1997), flooding (e.g., Hayden et al. 2007), or winter weather (e.g., Drobot 2007). 
The scope of the study allowed for about 12 participants. We sought interviewees with strong radar interpretation experience so that we would learn the limits of the instrument rather than of the training of the participants. Also, strong public communication experience would bring in that stakeholder's understanding of their user. Experience with other radars brought in broader knowledge of radar capabilities.

In the end, nine meteorologists participated from among the five NWS offices and TV markets near Norman, Oklahoma. Of the five NWS participants, four were managers, and one was in his fourth year as a warning forecaster. Years of experience ranged from 8 to over 25 . Of the four managers, two focused on scientific issues and two on external communications. The four broadcast participants worked at three different stations in two cities. Two had over $25 \mathrm{yr}$ experience; one was a station chief. Two had less than $10 \mathrm{yr}$ experience. One worked primarily off-camera as a weather producer. The other was a weekend morning meteorologist who often did field reporting during prime time severe weather. All five NWS participants had experience with WSR-74 radars, though two were relatively young. Two of the four broadcasters began their careers after WSR-88D deployment. Work histories were not specifically queried, but some participants mentioned having worked in the Northern Plains, the Southeast, or the western United States before moving to this region.

Interviews. In most cases, the interviewer (the first author of this article) did not know a participant before the interview. Rapport was established by asking each person to explain his or her role during weather events. In the main part of the interview, participants were asked to describe incidents in which radar provided-or failed to provide-information needed to perform their job. Finally, participants were asked to describe how information from current radar systems differed from that of other radar systems they had used. Participants were also asked to describe their ideal radar system.

Coding and thematic analysis. To make sense of the raw data from the interviews, we coded transcripts thematically. This helped in reorganizing data according to similar ideas and comparing ideas across interviews (Patton 2002). Because this was an open-ended exploration of stakeholder perceptions, we let the data drive the thematic analysis (Boyatzis 1998). Themes emerge naturally from the data rather than being preconceived by theory. Our themes were coded to show how strengths and weaknesses of the WSR-88D affected participants' abilities to do their jobs.

Codes derived from 45 incidents and other substantiated comments were organized into more than 80 categories and subcategories. By the ninth interview, most categories were found in multiple interviews. The 12 categories with a single mention were all well-known strengths or limitations included in current radar training courses (L. Quoetone 2009, personal communication). Several categories illustrated aspects of how radar strengths and limitations affected the participants' operations, which in turn became a category in itself. Participants' understanding and description of their jobs, absent in previous studies, provided critical context for how they used radar.

We grouped categories into four general themes, or radar needs, as shown in Figs. 1-5. When an incident implied more than one need, we placed it only in the figure portraying the most important need revealed in that experience.

Addressing trustworthiness. Biases and sources of error in qualitative research in the social sciences are proactively addressed in research design and analysis strategies, prior to results. For the CIT, specifically,

\section{ORIGIN OF THE CIT}

The practice of asking for critical incidents can be traced to the studies of Sir Frances Galton during the nineteenth century. However, the CIT as it is known today began to evolve during World War II. During that time, the U.S. Air Force needed a way to select and train pilots as quickly as possible. To help them attain that goal, the Air Force enlisted the help of John C. Flanagan and the newly formed Aviation Psychology Program (Flanagan 1954). Their initial study sought to determine why $I, 000$ pilots had failed training programs and how these programs could be better designed to produce competent pilots. An examination of pilot evaluations revealed many general, stereotypical statements - "lack of inherent flying ability," "poor judgment," "insufficient progress." Flanagan asserted that it would be much more useful if the evaluations described incidents in which pilots showed these qualities.

To attain this information, Flanagan developed a questionnaire and distributed it to flight instructors, asking them about pilots' behavior during critical situations, and why this behavior was either effective or ineffective. The information gained from their study helped to develop a new training program for pilots (Flanagan 1954). Under the guidance of Flanagan, the CIT was developed further and given its present name. The CIT is now a common and well-respected method in qualitative research. 


\section{The Experience}

By combining radar with other data, forecasters make the best of the science. Overall, the WSR-88D network has great strength in providing critical information. It is a relatively dense, reliable network with updated information about every $5 \mathrm{~min}$. Forecasters are most confident of data within $50 \mathrm{mi}$ of the radar. As distance increases, they make greater use of other data and they are less confident.

Broadcasters said radar imagery helps convey threats to viewers. They could trust WSR-88D data to be clean. Trends from volumetric data helped assess severity. They relied on WSR-88D for velocity information and data from which to build long, large-scale loops.

Forecasters attempt to link volumetric radar information to conceptual knowledge of storm processes. They look for a variety of features ranging from bounded weak echo regions to 3-body scatter spikes, storm top divergence, rear inflow jets, and tornadoes embedded in precipitation areas.

Forecasters find it useful for themselves and other officials to make novel use of radar. Examples included detecting smoke from wildfires and identifying paths of space shuttle debris.

Forecasters sometimes had to hurriedly intervene when an important storm became obscured by range folded velocity data; or had to quickly change the VCP to regain important velocity information. Similarly, a forecaster said he wished the radar could automatically switch to the most appropriate rain rate relationship.
Strengths of the Current System

Radar is often first and/or only source of data to indicate what is happening. Rain gages are far apart and reporting intervals vary. Other data is sparse (e.g., surface) or simply less useful in a definitive sense (e.g., satellite).

Volumetric data helps in determining storm type, severity, and current and likely threats.

Data are clean, accurate, and reliable. Trend, velocity, rainfall, and other key aspects of WSR-88D data helps convey threats to viewers.

Radar data helps forecasters provide support to other officials managing local situations.

Limitations of the Current System

Having to manipulate the radar system takes critical time away from monitoring, interpreting, and making warning decisions. study precluded widening participation beyond this region, results show strong agreement and no new concepts emerged during the last few interviews.

Another bias could arise from when and where data were collected because the interview format, by nature, brings out whatever issues are prominent in the interviewee's mind (Patton 2002). The interviews probed a wide variety of significant weather situations.

The last potential bias for a CIT study is interpretation. Diagrams show readers how incidents were interpreted and grouped. All incidents pertaining to weather events are reported here; other incidents are included in the supplement. Recommendations are preceded by immediate questions that frame this study and discourage readers from generalizing inappropriately.

A final, common step in qualitative research is participant review (Patton 2002); participants were twice given drafts of results it is important to address biases at all steps in the research process (e.g., Flanagan 1954).

Interrater reliability helps reveal biases in the interpretation (Patton 2002). Two of us (DL and JN) independently coded transcripts and grouped codes into themes. We selected one interview at random for a thorough comparison of these codes. Only minor changes were made to align the two coding schemes. Our coding was likely repeatable and reliable. It is unlikely that any important issues were overlooked.

Bias can arise from who and how many participate in the study, just as the type and number of cases in a meteorological study will bias the results. Our sampling strategy included the use of multiple locations, forecasters with key roles internal and external to the office, and experience with a variety of radars. Although time and funding for this demonstration (including Newman et al. 2008) and asked whether those drafts fairly represented their points of view. Eight of the nine participants provided comments with minor to no concerns; the ninth participant did not respond to two attempts at contact.

\section{PARTICIPANTS' PERSPECTIVES ON THEIR}

WORK. During analysis it became clear that participants viewed themselves as part of what has been called the integrated warning system (Doswell et al. 1999), an ad hoc system of disparate parts that usually try to function in harmony, each adding value. Our participants conveyed that their work complemented and depended upon the others', supporting Doswell et al.'s proposition. Participants' views of their work also provided a fundamental context for understanding how successes and issues with current radar technol- 
ogy manifested in their operations. We present these views first to help with interpretation of incidents described in the interviews. (For brevity, "broadcaster" refers to our broadcast meteorologist participants, and "forecaster" to our NWS forecaster participants. "Participant" refers to both groups.)

Forecasters said their main task was to make the best forecasts and warnings possible using the latest tools and scientific understanding of weather. During weather situations where radar was a primary tool, one or more forecasters were dedicated to interpreting radar and issuing warnings. During other situations, including winter weather, routine assignments such as the shortterm forecast desk became the office's most critical responsibility. While some forecasters assessed the current and anticipated state of the atmosphere and issued public products, others coordinated and monitored external communication to provide forecasters with weather reports and assist certain user groups, such as city or county officials. Occasionally forecasters worked directly and on site at incident command posts.

Some forecasters characterized a portion of their task as driving the warning notification process. Although NWS products are publicly available, participants knew that most people receive a message repackaged by a broadcaster, emergency manager, or other partner in this ad hoc integrated warning system. According to one forecaster,

We're responsible for issuing the warnings, forecasts, and providing weather information to ... a wide set to rapidly update. radar systems.

b) a) The Experience

Forecasters have seen others manually restart a volume scan to get another low-altitude scan quickly.

Broadcasters simply rely on station radars, which can be

Forecasters spoke about the importance of process, of seeing a precipitation core catch up to outflow winds, meaning severe winds were imminent. Both groups said the inability to see rapid evolution between storm types compromisd their ability to make the best warning and coverage decisions.

Forecasters want to be able to warn before a downburst is affecting ground level, meaning they want to observe pre-downburst radar signatures in storms. Participants from both groups said that downburst type events were one of the most difficult to detect with current

\section{The Experience}

Forecasters have used changes in the character of clear air echoes to monitor environmental changes prior to storm formation.

Meteorologists can misunderstand the true nature of a threat and subsequently not warn or not include verbiage appropriate to the threat. A broadcaster noted that trends are important in making coverage decisions, but trends can be misleading.

See also "Tilted/sheared storms" in Fig 3. Both groups want to minimize unnecessary actions. They have learned how warnings are disruptive to individuals, while taking action for a tornado that would not have affected him. schools, businesses, etc; one knew of someone dying
Limitations of 4-6 min Updates

Storms can transition from nontornadic to tornadic states in 10 s of seconds.

Evolution and transitions between storm type and evolution of circulations on gust fronts can occur between scans.

The motion in a downburst type event is tangential to the radar. A divergence couplet at the ground means the event is already in progress. Mid- and upper-level signatures are not reliably detected.
What Is Needed:

Higher-temporal resolution data
FIG. 2. As in Fig. I, but showing how (a) 4-6-min update limitations and (b) the strength of clear-air scanning and limitations of current sampling implied a need for higher-temporal- or higher-spatial-resolution data.

What Is Needed:

Higher-spatial resolution data

Limitations of Current Sampling

Some mesocyclone circulations, especially those in mini-supercell storms, appear weaker than they really are when far from the radar. Trends of storm characteristics can ${ }^{F}$ underestimate severity because of beam spreading.

Warnings encompass a larger area than any possible tornado damage path, and generally increase in size with distance from the radar due to uncertainty in ground location, in part because of beam spreading 
is the basis for most warnings. A major part of our role is to make sense of NWS information, then add to it, using our station radars and spotters. We need to better define where and what the threat really is in order to help our viewers. ${ }^{1}$

All of the broadcasters had high-resolution, shortwavelength station radars capable of 30-s to 1-min low-elevation angle updates. Broadcasters said they often showed radar images on the air to illustrate the current weather threat to viewers, and that on-air interpretation was sometimes required to help viewers understand what they were seeing. Participants all had meteorology degrees and said it was difficult to do a sophisticated radar analysis mentally while providing simple, understandable information to their viewers. They examined their high-spatial- and high-temporal-resolution data at the lowest elevation angle and received information from trusted spotters, so they could interpret and narrow down the threat area within NWS warnings.

Broadcasters could best do their jobs when they understood the reasoning behind warnings, which was often missing in NWS products. Knowledge of imminent warnings, when available, also helped them make wiser decisions about when to cut in with severe weather coverage and what information to show or discuss on the air. Participating in the relatively new NWSChat (https://nwschat.weather. gov/) with their local NWS office could provide such information, and some broadcasters used that tool to share information from spotters and viewers with the NWS.

These findings illustrate key differences between the two stakeholder groups. In describing incidents, NWS forecasters emphasized scientific assessment, while broadcasters emphasized adding meaning to the weather information. The most significant feed-

\section{The Experience}

Broadcaster participants spoke at length about using their station radars to better observe several small, rapidly evolving, damaging tornadoes in recent years. A forecaster with access to TDWR said he saw aspects of storm evolution he knew occurred, but could not observe with WSR-88D.

\section{Limitations of 4-6 min Updates}

Significant changes in hazardous weathe often occur on small temporal and spatial scales.
Reliable, clean
intervention.

My job became a lot easier after the WSR-88D was deployed. That radar network led to significant improvement in the quality of warnings issued by the

National Weather Service.-Broadcaster

This theme, illustrated in Fig. 1, emphasizes strengths of the WSR-88D network. Any participant who compared the WSR-88D with past networks asserted that the WSR-88D network was a significant step forward. Participants from both groups emphasized that the WSR-88D network provided a critically important and unique dataset that dramatically improved their ability to do their job in three ways. First, the data were more frequent with better areal coverage than any other source of weather data. Radar was

\footnotetext{
${ }^{1}$ Forecasters allowed direct quotation, while broadcasters did not. Thus, broadcaster statements are paraphrases of their original comment.
} 
often the first, and sometimes the only, source of data that indicated what was happening, and the data were essentially available every $5 \mathrm{~min}, 24$ hours a day, 7 days a week, and 365 days each year.

Second, broadcasters in particular noted that they could rely on WSR-88D data to be clean and accurate, and ready for graphics with minimal monitoring. While shorter-wavelength station radars were configured with distinct advantages over WSR-88D (see later discussion), broadcasters sometimes dealt with smeared reflectivity fields, significant second-trip echo problems, and attenuation in heavy storm cores. Forecasters did not convey stories centered on data quality, except where quality issues required them to intervene (below). from the NWS and kept viewers informed of changes in storm strength. Forecasters also mentioned occasional use of volumetric information in nonweather events (see Fig. 1).

While the WSR-88D system was generally lauded, forecasters expressed one frustration: they must occasionally take valuable time away from data analysis and creation of public products to intervene. This finding is unique to this study. First, they sometimes must change the pulse-repetition frequency (PRF), which is inversely related to the maximum unambiguous range, to avoid losing information on storms moving through areas of range folded velocities. Second, they must sometimes change the $Z-R$, or rain-rate relationship used by the radar, to improve
[I use volumetric data] to look for features that I know are associated with severe storms, like bounded weak echo regions, high reflectivity cores aloft, three-body scatter, mesocyclones, storm-top divergence, all sorts of things.-Forecaster

Third, WSR-88D data provide critical volumetric information. Forecasters specifically cited the radar as a primary tool during severe weather that helped them relate scientific, $3 \mathrm{D}$ conceptual models to storm processes that radar either directly or indirectly indicated, such as bounded weak echo regions, elevated high-reflectivity cores, the strength of storm updrafts, rear-inflow jets to storm complexes, mesocyclones, storm-top divergence, and much more. In contrast, broadcasters used volumetric information mainly for monitoring the early phases of storms to help them decide when and how to cover the event. For example, they tried to anticipate warnings

\section{The Experience}

Both groups struggle to learn what echoes should look like at varying distances, and continually struggle to remain cognizant of the varying height-above-ground of radar echoes.

As before, it is as important to accurately not warn as much as it is to accurately warn. People are disrupting their lives to take action when they won't be affected by the weather; some have died taking such actions.

A broadcaster knew of at least one instance where a media spotter observed a relatively brief tornado that was unwarned. There may have been a boundary/storm intersection but it was not explicitly observed due to radar horizon.

A recent large tornado, for example, was on the ground for 6-7 miles before there was a classic radar signature. When there is a midlevel circulation, meteorologists need to know how far down that circulation extends to determine the likelihood of a tornado occurring.

Forecasters have seen events where the actual tornado location was miles different than the radar signature. Even close to the radar, broadcasters add information from station radars and storm spotters in careful attempt to pinpoint tornado threats for viewers.

Forecasters struggled to adequately handle some recent tropical flooding events because gages did not provide enough rainfall information. Radar was critical, but inadequate in the event.

Meteorologists said they use the lack of an echo near the radar to infer whether snow is reaching the ground, but that could only be true for a portion of their areas of responsibility! Nighttime snow events are particularly difficult because they have few spotter/viewer reports until morning.

\section{Limitations of Network Configurations}

The physics of radar sampling leads to increasing of the sampled height-aboveground as distance from the radar increases.

Information underneath mesocyclones, needed to assess likelihood of tornado formation, is not sampled at long distances from the radar.

Information at low levels is required to see boundary-storm intersections; tornadoes can form at these intersections.

Some tornadoes form without midlevel mesocyclones. Information about how far down a circulation extends is important for other warning decisions.

Most storms are tilted or sheared from the vertical, meaning tornado-ground intersection is usually displaced from the midlevel mesocyclone.

Tropical rainfall is distributed in the lower altitudes of storms, so may be below the radar horizon.

Snow can either grow or evaporate below the radar horizon.

What Is Needed:

Consistent and low-altitude information throughout area

FIG. 4. As in Fig. I, but showing how limitations in the network configuration of the WSR-88D implied a need for consistent and low-altitude information throughout the area of responsibility. 
precipitation estimation. One forecaster in a management role said he watched for those instances so he could proactively mitigate potentially interrupted or unusable data.

Higher-resolution data. Three limitations of the 4-6-min update interval of WSR-88D data were derived from participants' stories, indicating a need for highertemporal-resolution data. Two limitations of current spatial sampling indicated a need for higher-spatialresolution data (Fig. 2). Broadcasters and one forecaster emphasized both limitations together (Fig. 3) because other radar systems show what the WSR-88D misses.

You go storm-chasing and we see how fast tornadoes form, how fast they dissipate, how they get from sort of small-looking to big-looking and vice versa. These things happen very quickly. And when a volume scan takes five minutes, a lot of things can change character in five minutes.-Forecaster

\section{The Experience}

Both river and rain gages are sparse and report access can be cut off during flooding. Both groups said radar provides valuable qualitative information on distribution of precipitation. Broadcasters routinely use precipitation accumulation imagery on-air to help convey distribution and impacts of weather events.

Both groups attempted to use radar during winter precipitation to infer whether snow might be reaching the ground, track areas of heavier precipitation, identify bands of heavier snow, and identify where precipitation type might be changing from one type to another.

Broadcasters want to convey precipitation threats to viewers and their software makes it easy to click and display a precipitation estimation for viewers. Unfortunately they have found that WSR-88D provides questionable, often incorrect precipitation amounts. Forecasters said flash flood warnings are a major part of their responsibility but radar-estimations can be far off.

One forecaster's story pointed out that there is a significant difference in the damage resulting from small vs. large hail driven by $60-70 \mathrm{mph}$ winds. A broadcaster said he wanted to convey hail threats because viewers can avoid some hail damage by, for example, moving vehicles into garages.

Both groups rely on ground truth information for good forecasts and warnings, but it is difficult to attain at night. relatively infrequently; some river gages are manual and

\section{Strengths of Single Polarization}

Radar provides a qualitative assessment of the distribution of precipitation with updated information throughout the area every $5 \mathrm{~min}$.

Radar provides hints about the onset, type, intensity, and total precipitation in winter.

\section{Limitations of Single Polarization}

Need to know how much precipitation has fallen; the two Z-R relationships are inadequate.

Must currently infer whether hail is present and how big it is; need to know the distribution of types and sizes of hydrometeors in general.

More definitive information is needed about the onset, type, intensity, and total precipitation in winter.

\section{What Is Needed:}

Precipitation type, size, distribution, and intensity

FIG. 5. As in Fig. I, but showing how the strengths and limitations of single polarization implied a need for precipitation type, size, distribution, and intensity. ce of those processes while broadcasters set their radars to scan only the lowest elevation at a high scan rate. Both sought to provide lead time, but station computing resources and time constraints usually precluded broadcasters from doing their own 3D analyses.

Downbursts were a distinct issue. Precursors to downburst-type events were very difficult to detect because the infrequent sampling of WSR-88D does not capture the falling core of the storm cell. Forecasters look for upperlevel indications, but those are inadequately sampled to reliably indicate an imminent downburst. Participants from both groups pointed out that low-altitude divergence signatures may not be sampled at all, and when sampled, indicated a downburst already in progress.

A single strength gleaned from participants' 
stories is that the spatial resolution of WSR-88D allows forecasters to see the character and changes in clear-air echoes to assess whether the environment is becoming more conducive to storm formation.

Once storms had formed, warnings were issued with a different mindset if they were located far from the radar. For example, in one story a mesocyclone far from the radar appeared weaker than it really was because of the poor spatial sampling that occurs from beam spreading. One broadcaster described an instance in which he was frustrated to not know exactly what was happening with a storm about 100 miles away. Because of coarse spatial resolution, warnings encompass a far greater area than any possible tornado damage path. Both groups expressed frustration: forecasters said it was just as important to not warn as it was to warn, and broadcasters similarly wanted to help people know when they would not be affected. In several stories, broadcasters had confidence to further specify the threat within a warning issued by the NWS, relying on live storm chaser reports and their high-spatial-resolution radars.

Participants reported using shorter wavelength radars to obtain higher temporal and spatial resolution data (Fig. 3). Broadcasters reported frequently setting their radars to scanning modes that made storms appear to be alive. They observed incredible detail in tornado formation, evolution, and location. A forecaster echoed this sentiment, saying that TDWR was helping him see aspects of evolution he knew were happening but could not observe with the WSR-88D. Participants from both stakeholder groups conveyed a strong desire to issue narrower but accurate tornado warnings; detect and warn for small, brief, damaging circulations; detect downbursts prior to occurrence; and accurately assess storm type, strength, and transitions.

\footnotetext{
We know so much more about what is happening when using our station radar! We see many little circulations that have probably been there all along. Some are less than a mile across, but our spotters see these small tornadoes, too. They are real and they produce minor damage.-Broadcaster
}

Optimizations to achieve the above, however, resulted in poor velocity information and significant second-trip echo problems. The data were also subject to blurring or smearing in fast-scan mode. One broadcaster displayed archive station radar data that showed incredibly fine detail in a hook echo that the local WSR-88D, only 12 miles away, could not resolve well. This broadcaster showed that he had to zoom in on the particular storm to use his data on the air second-trip echoes from other storms pervaded parts of his display.

\section{Consistent and low-altitude information throughout the area.}

Sometimes we have tornado warnings because we can't tell enough about the negative side of it. All we know is that it has a strong midlevel mesocyclone, but I can't see low-level gust front features to see if the storm is undercut. So you may have a tornado warning at longer ranges, simply because of uncertainty.-Forecaster

The current WSR-88D network configuration significantly affects where low-altitude information is obtained (Fig. 4). Factors include distance between radars, sites in complex terrain, curvature of the Earth, and atmospheric refraction. Radar siting results in gaps in low-altitude coverage. The latter two factors result in a radar beam that generally increases in height with increasing distance from the radar. Experienced forecasters reported observing younger forecasters struggle to learn how storm features vary in appearance as storms move through a radar domain. Most of the stories grouped here involved missing low-altitude information critical to assessing weather hazards.

When discussing tornadoes, the importance of low-altitude data was illustrated by participants in four ways. First, low-altitude information was important for knowing if there was surface-based convergence beneath the mesocyclone when tornado formation appeared likely. Second, low-altitude information could also show where boundaries intersected storms, increased shear, and made tornadoes more likely. Third, low-altitude information was critical to both confidence in issuing tornado warnings and to reducing the size of them. Several tornadoes in participants' stories, including one violent tornado, began without a significant midlevel signature. A violent tornado had produced damage for about six miles before a classic radar signature was present. Finally, storms are usually tilted or sheared from the vertical, meaning the higher the minimum altitude sampled, the greater the uncertainty in location of ground contact for a tornado.

Low-altitude radar information was crucial for accurate precipitation estimation. In tropical rainfall regimes, most of the precipitation is distributed in lower altitudes. Snow totals were similarly difficult to determine because snow can either grow or evaporate in the poorly sampled lower altitudes. In both cases, 
participants were left to rely on spotter/viewer reports and gauge and surface data that are sparse in time and space. Nighttime events of both types were therefore particularly problematic, because few reports came in. As is clear from the next section, precipitation issues were significant to participants and deserving of an entire category.

\section{Precipitation type, size, distribution, and intensity.} I will at least guess at what is happening based upon information from radar because my viewers want to know. For example, a bright band indicates the freezing level. In some cases, that can help me guess where a freezing rain vs. sleet line, or a snow vs. rain line might be.-Broadcaster

The above statement shows that participants found important utility in precipitation information, despite the general indeterminacy of precipitation information (Fig. 5). The WSR-88D network was helpful, assisting participants in knowing the areal extent and distribution of rainfall. This could be critical, for example, as sometimes a first indicator of flooding. Broadcasters also routinely used large-scale precipitation accumulation maps to illustrate overall storm system movement to their viewers. Radar data were somewhat helpful in winter precipitation situations, indicating areas of heavier precipitation and sometimes transitions in precipitation type. Generally speaking, however, radar was poor at indicating frozen precipitation types, accumulations, and impacts. Both groups emphasized the importance of spotter/ viewer reports for precipitation information.

It is easy for me to display radar-derived precipitation totals on air-see how it is a simple click of a button? But I cannot trust it. So I go out of my way to use rainfall amounts from gauges. I know how far off radar estimates can be.-Broadcaster

In tropical rain situations ... [rainfall totals] can be underestimated by a factor of 2 . And some of those rainfall totals may exceed $10 \mathrm{in}$. at night. So it's a big deal.-Forecaster

Providing flash flood warnings was conveyed as a major function of NWS, but forecasters said radarderived precipitation estimates were often inaccurate, challenging their ability to perform this function well. They described changing the $Z-R$ relationship, but the options were inadequate for the range of weather events they experienced in the Southern Plains. Participants from both groups emphasized using ground truth to verify amounts when possible, and not trusting precipitation estimates unless corroborated.

Detection of hail was a second major issue raised in interviews. Hail is often the basis upon which severe thunderstorm warnings are issued, but the current WSR-88D configuration does not directly detect hail. Forecasters cited using three-body scatter spikes, the height and strength of reflectivities in certain temperature ranges, and environmental information to help decide the likelihood of hail. However, this was inadequate. One forecaster pointed out that hail impacts varied significantly depending on the hail size. The same echo could mean there were large amounts of pea-sized hail or smaller amounts of baseball-sized hailstones that caused significant and widespread damage. Broadcasters would like to convey the likelihood of hail because viewers can mitigate damage, for example, by moving vehicles into garages. One broadcaster who sometimes did field reporting said he is now skeptical of radar-estimated hail sizes and has become increasingly daring to drive into storms to see what is there.

Finally, participants in both groups related problems in providing accurate information during winter, when hazards tend to develop nearly in situ in the Southern Plains. Participants need to know the onset, type, and intensity of winter precipitation. Radar was poor at indicating frozen precipitation types, which was critical in forecasting accumulations and impacts.

Many of the needs discussed above will soon be addressed by the addition of dual-polarization capability to the WSR-88D network (e.g., Ryzhkov et al. 2005; Scharfenberg et al. 2005). The dual-polarization upgrade will include a suite of algorithms that discriminate meteorological from nonmeteorological echoes and classify a set of hydrometeor types, such as rain, hail, and snow (Park et al. 2009). This upgrade will also include precipitation estimation algorithms that will significantly improve accuracy of rainfall rates and amounts (Giangrande and Ryzhkov 2008).

Remaining questions. This study design could be applied to other regions for a more complete understanding of issues for radar replacement technologies. We would first be interested to know if there are additional types of radar-detectable weather not commonly experienced by these participants. (Readers are encouraged to review additional information online at http://dx.doi.org/2009BAMS2830.2 to review weather types covered in this study.) Similarly, would broadening the study to other regions reveal additional important, novel uses of weather radar? 
Finally, do forecasters and broadcasters in other regions similarly envision their roles within the ad-hocintegrated warning system?

CONCLUSIONS. Our application of CIT-the first in the field of meteorology-identified four radar needs for forecasters and broadcasters in the Southern Plains. These radar needs corroborate those found by the JAG/PAR study that polled agency needs (OFCM 2006). This study explains those operational issues in greater depth, however, and is the first to include a stakeholder group from outside the federal government. The need to intervene to maintain useful data was a unique finding, as was how participants depicted their operations. By synthesizing information from critical incidents, this work also adds how these radar issues impact users' job performance.

The WSR-88D network both enables and inhibits two key stakeholder groups in their work. Their experience shapes expectations about performance and/or service improvements if the next radar system addresses the limitations described herein.

ACKNOWLEDGMENTS. The authors are grateful for the time our participants were able to spend with us and their willingness to provide insight on their important roles. Thanks go to the 7 October 2008 attendees of the Experimental Warning Program Brown Bag Lunch and to Harold Brooks and Heather Lazrus for their helpful comments. The Warning Decision Training Branch helped refine descriptions of radar issues. Thanks to two anonymous reviewers, Daniel Nietfeld, our subject editor, Dr. Rebecca Morss, and Mr. Jeff Rosenfeld for their helpful suggestions during review.

This work was prepared by the authors with funding provided by NOAA's Office of Oceanic and Atmospheric Research under NOAA-University of Oklahoma Cooperative Agreement NA17RJ1227, the U.S. Department of Commerce, and National Science Foundation Grant ATM-0648566. The statements, findings, conclusions, and recommendations are those of the author(s) and do not necessarily reflect the views of NOAA, the U.S. Department of Commerce, or the National Science Foundation.

\section{REFERENCES}

Boyatzis, R. E., 1998: Transforming Qualitative Information: Thematic Analysis and Code Development. Sage Publications, $184 \mathrm{pp}$.

Crum, T. D., R. E. Saffle, and J. W. Wilson, 1998: An update on the NEXRAD program and future WSR-88D support to operations. Wea. Forecasting, 13, 253-262.
Doswell, C., III, A. R. Moller, and H. Brooks, 1999: Storm spotting and public awareness since the first tornado forecasts of 1948. Wea. Forecasting, 14, 544-557.

Drobot, S., 2007: Evaluation of winter storm warnings: A case study of the Colorado Front Range December 20-21, 2006, Winter Storm. Natural Hazards Center Quick Response Report QR192, 8 pp. [Available online at www.colorado.edu/hazards/research/qr/ qr192/QR192.pdf.]

Dunn, W. R., and D. D. Hamilton, 1986. The critical incident technique: A brief guide. Med. Teach., 22, 207-215.

Flanagan J. C., 1954: The critical incident technique. Psych. Bull., 51, 327-359.

Giangrande, S. E., and A. V. Ryzhkov, 2008: Estimation of rainfall based on the results of polarimetric echo classification. J. Appl. Meteor. Climatol., 47, 2445-2462.

Hayden, M. H., S. Drobot, S. Radil, C. Benight, E. C. Gruntfest, and L. R. Barnes, 2007: Information sources for flash flood warnings in Denver, CO, and Austin, TX. Environ. Hazards, 7, 211-219.

Istok, M. J., A. Cheek, A. D. Stern, R. E. Saffle, B. R. Klein, N. Shen, and W. M. Blanchard, 2009: Leveraging multiple FAA radars for NWS operations. Preprints, 25th Conf. on Interactive Information Processing Systems for Meteorology, Oceanography, and Hydrology, Phoenix, AZ, Amer. Meteor. Soc., 10B.2. [Available online at http://ams.confex.com/ ams/89annual/techprogram/paper_145466.htm.]

Kraaijenbrink, J., 2007: Engineers and the Web: An analysis of real life gaps in information usage. Info. Process. Manage., 43, 1368-1382.

Legates, D. R., and M. D. Biddle, 1999: Warning response and risk behavior in the Oak Grove-Birmingham, Alabama, tornado of 08 April 1998. Natural Hazards Center Quick Response Report QR116. [Available online at www.colorado.edu/hazards/research/qr/ qr116/qr116.html.]

McLaughlin, D., and Coauthors, 2009: Short-wavelength technology and the potential for distributed networks of small radar systems. Bull. Amer. Meteor. Soc., 90, 1797-1817.

Morss, R. E., O. V. Wilhelmi, M. W. Downton, and E. C. Gruntfest, 2005: Flood risk, uncertainty, and scientific information for decision making: Lessons from an interdisciplinary project. Bull. Amer. Meteor. Soc., 86, 1593-1601.

National Academies, 2002: Weather radar technology beyond NEXRAD. Report prepared by the National Research Council, National Academy of Science, National Academy Press, 96 pp. [Available online at www.nap.edu/catalog.php?record_id=10394.] 
— , 2008: Evaluation of the multifunction phased array radar planning process. Report prepared by the National Research Council, National Academy of Science, National Academy Press, 79 pp. [Available online at www.nap.edu/catalog.php?record id=12438.]

Newman, J., D. LaDue, and P. L. Heinselman, 2008: Identifying critical strengths and limitations of current radar systems. Preprints, 24th Conf. on Severe Local Storms, Savannah, GA, Amer. Meteor. Soc., 7B.5. [Available online at http://ams.confex. com/ams/89annual/techprogram/paper_148096. htm.]

OFCM, 2006: Federal research and development needs and priorities for phased array radar. Rep. FMC-R25-2006, Interdepartmental Committee for Meteorological Services and Supporting Research, Committee for Cooperative Research Joint Action Group for Phased Array Radar Project, 62 pp. [Available online at www.ofcm.gov/r25-mpar/fcm-r25. htm.]

Oliver, D., and J. Roos, 2003: Dealing with the unexpected: Critical incidents in the LEGO Mindstorms team. Human Relations, 56, 1057-1082.

Park, H., A. Ryzhkov, D. Zrnić, and K-E. Kim, 2009: The hydrometeor classification algorithm for the polarimetric WSR-88D: Description and application to an MCS. Wea. Forecasting, 24, 730-748.

Patton, M. Q., 2002: Qualitative Evaluation and Research Methods. 3rd ed. Sage Publications, 688 pp.

Ryzhkov, A.V., T. J. Schuur, D. W. Burgess, P. L. Heinselman, S. E. Giangrande, and D. S. Zrnić, 2005: The Joint Polarization Experiment: Polarimetric rainfall measurements and hydrometeor classification. Bull. Amer. Meteor. Soc., 86, 809-824.

Scharfenberg, K. A., and Coauthors, 2005: The joint polarization experiment: Polarimetric radar in forecasting and warning decision making. Wea. Forecasting, 20, 775-788.

Schluter, J., P. Seaton, and W. Chaboyer, 2008: Critical incident technique: A user's guide for nurse researchers. J. Adv. Nurs., 61, 107-114.

Schmidlin, T. W., and P. S. King, 1997: Risk factors for death in the 1 March 1997 Arkansas tornadoes. Natural Hazards Center Quick Response Report QR98. [Available online at www.colorado.edu/ hazards/research/qr/qr98.html.]

Serafin, R. J., and J. W. Wilson, 2000: Operational weather radar in the United States: Progress and opportunity. Bull. Amer. Meteor. Soc., 81, 501-518.

Simmons, K. M., and D. Sutter, 2008: Tornado warnings, lead times, and tornado casualties: An empirical investigation. Wea. Forecasting, 23, 246-258.

Steadham, R., 2008: 2008 National Weather Service field study. Part 1: Volume coverage pattern usage. Radar Operations Center, Norman, OK, 28 pp. [Available from WSR-88D Radar Operations Center, 1200 Westheimer Dr., Norman, OK 73069.]

Whiton, R. C., P. L. Smith, S. G. Bigler, K. E. Wilk, and A. C. Harbuck, 1998: History of operational use of weather radar by U.S. Weather Services. Part II: Development of operational Doppler weather radars. Wea. Forecasting, 13, 244-252.

Zrnić, D. S., and Coauthors, 2007: Agile beam phased array radar for weather observations. Bull. Amer. Meteor. Soc., 88, 1753-1766.

\section{Mid-Latitude Weather Systems}

Mid-Latitude Weather Systems is the first text to make extensive use of conventional weather charts and equations to fully illustrate the behavior and evolution of weather patterns.

Presenting a fusion between the mathematical and descriptive fields of meteorology and integrated coverage of synoptic and dynamic approaches, Mid-Latitude Weather Systems provides students with an invaluable course text and reference source to gain an unclouded appreciation of the underlying processes and behavior of midlatitude weather patterns.

Mid-Latitude Weather Systems: \$52/list, \$42/AMS members, or \$32/students.

Order Online: www.ametsoc.org/amsbookstore

or use the order form in the back of this issue. 